Published in final edited form as:

J Res Read. 2005 August ; 28(3): 332-349.

\title{
The effect of print size on reading speed in dyslexia
}

\author{
Beth A. O'Brien \\ Eliot-Pearson Department of Child Development, Tufts University, USA
}

J. Stephen Mansfield

Department of Psychology, State University of New York at Plattsburgh, USA

Gordon E. Legge

Department of Psychology, University of Minnesota, USA

\section{Abstract}

This article details a study which predicted that across a wide range of print sizes dyslexic reading would follow the same curve shape as skilled reading, with constant reading rates across large print sizes and a sharp decline in reading rates below a critical print size. It also predicted that dyslexic readers would require larger critical print sizes to attain their maximum reading speeds, following the letter position coding deficit hypothesis. Reading speed was measured across twelve print sizes ranging from Snellen equivalents of 20/12 to 20/200 letter sizes for a group of dyslexic readers in Grades 2 to 4 (aged 7 to 10 years), and for non-dyslexic readers in Grades 1 to 3 (aged 6 to 8 years). The groups were equated for word reading ability. Results confirmed that reading rate-by-print size curves followed the same two-limbed shape for dyslexic and non-dyslexic readers. Dyslexic reading curves showed higher critical print sizes and shallower reading rate-by-print size slopes below the critical print size, consistent with the hypothesis of a letter-position coding deficit. Non-dyslexic reading curves also showed a decrease of critical print size with age. A developmental lag model of dyslexic reading does not account for the results, since the regression of critical print size on maximum reading rate differed between groups.

\begin{abstract}
Developmental dyslexia, a learning disability specific to reading, affects an estimated 5\% of children in school. Reading requires processing of both the visual information from the page and the linguistic information that the print represents. Over a century of research on causal factors in developmental dyslexia has emphasised either one or the other of these processes, beginning with theories of visual causation. Morgan (1896) coined the inability to read in children as 'congenital word blindness', while Orton (1928) described the phenomenon of 'strephosymbolia' (twisted symbols), where children could read mirror-image writing more easily. The current view of dyslexia holds that reading failure is caused by a linguistic deficit in coding phonemes (individual speech sounds) within words, and thereby in accessing and manipulating these phonemic codes as required on a wide range of tasks (phonological processing) (Snowling, 2000). This view holds that a phonological processing deficit impedes a child's ability to develop phoneme awareness, to learn grapheme-phoneme correspondence rules, and to decode words (Liberman et al., 1974; Stanovich \& Siegel, 1994). The theory accounts for many cases of developmental dyslexia, but there are individuals with dyslexia who do not demonstrate a severe phonological deficit (Wolf \& Bowers, 1999; Lovett, Steinbach $\&$ Frijters, 2000). Also, remediation programmes aimed at training phonological skills are often but not entirely successful (Lyon \& Moats, 1997; Torgesen, 2000). This suggests a need for alternative or additional accounts of causal factors in dyslexia.
\end{abstract}

Correspondence to: Beth A. O'Brien.

Address for correspondence: Beth O'Brien, Ph.D., Rhode Island College, 600 Mount Pleasant Avenue, Providence, RI 02908. E-mail: bobrien@ric.edu. 
Recent evidence shows that subtle impairments in visual processing characterise some individuals with dyslexia. Specifically, impaired processing is found for low spatial and high temporal frequency visual stimuli (Lovegrove et al., 1980; Martin \& Lovegrove, 1987; Talcott et al., 1998; but see also Skottun, 2000; Walther-Muller, 1995). The most robust of these findings indicates a particular problem with visual motion processing (Cornelissen et al., 1994; Demb et al., 1998; Talcott, Hansen, Elikem \& Stein, 2000; Everatt, Bradshaw \& Hibbard, 1999). Low spatial frequency, high temporal frequency and motion information are carried primarily via one of two parallel retino-cortical pathways in the human visual system: the magnocellular pathway. Thus, a unifying theory of visual factors in dyslexia holds that there is a magnocellular channel deficit. Neuroanatomic (Galaburda \& Livingstone, 1993; Livingstone, Rosen, Drislane \& Galaburda, 1991) and fMRI (Eden, van Meter, Rumsey, Maisog \& Zeffiro, 1996; Demb, Boynton \& Heeger, 1997) evidence consistent with this hypothesis corroborates the perceptual findings. Yet it is still unclear whether these visual deficits represent a correlate or a cause of reading problems. A direct causal link between vision and dyslexia is suggested by findings and observations where reading under demanding visual conditions, such as with small print, leads to declines in reading performance by dyslexic individuals (Cornelissen, Bradley, Fowler \& Stein, 1991; Skottun, 2001).

Cornelissen et al. (1991) found that reading errors decreased with larger print size for reading disabled children with poor binocular control, suggesting a causal link between a stressed visual system and reading impairment. Our previous study (O'Brien, Mansfield \& Legge, 2000) also implicated a potential effect of print size, where dyslexic readers require larger print sizes than normal readers to achieve their maximum reading speed. The print size effect was observed between subjects where the group difference in reading speed was greatest with small print, but the number of participants with repeated measures data across print sizes was too small to warrant a firm conclusion. Skottun (2001) noted the importance of demonstrating a parametric dependence of dyslexic reading on a visual variable, and pointed to this potential print size effect in our data. Such an effect would support a link between vision and dyslexia because a purely phonological explanation would not predict an effect of print size.

It is possible that larger print size facilitates dyslexic reading by increasing the visibility of spatial frequencies critical for letter recognition (Solomon \& Pelli, 1994) or reading (Legge, Pelli, Rubin \& Schleske, 1985). In addition, it is possible that dyslexic readers require a wider spatial-frequency bandwidth for reading than the two cycles per letter measured by Legge et al. (1985). For example, with larger letters, more distinguishing letter features may be available within the two cycle/character critical bandwidth for reading. Dyslexic readers may require more or different sets of features to distinguish between letters within words either because they are less efficient at picking up this visual information than skilled readers, or because their memory store of letter templates to match to incoming information is less well established. Other related factors that could be ameliorated with larger print include lateral masking ('crowding') effects, that may be greater in dyslexic readers (e.g. Geiger \& Lettvin, 1987, but see also Klein et al., 1990), or differences in visual span, that is, the number of letters recognisable in a glance (Legge, Ahn, Klitz \& Luebker, 1997; Legge, Mansfield \& Chung, 2001).

An alternative account of observed print size effects is that they could result from a general magnocellular deficit, which has been proposed to interfere with letter position coding (Cornelissen et al., 1998a, 1998b). The magnocellular channel provides the primary input to the dorsal occipito-cortical pathway, the so-called 'where' pathway that carries information about an object's position in space (Mishkin, Ungerlieder \& Macko, 1983). For reading, fidelity of the magnocellular channel should help to localise correctly the serial position of letters within words, and a dysfunction could lead to improper letter localisation and therefore reading errors (Cornelissen \& Hansen, 1998). In this case, it may not be the visibility of certain letter features, 
but instead their relative position within words that is affected by the size of the letters. It could be that deficient position signals have a bigger impact for very small letters whose relative position is harder to identify, and so may result in poorer reading performance with small print.

A magnocellular dysfunction in dyslexic reading has also been related to deficits in visual attention (Iles, Walsh \& Richardson, 2000; Pammer \& Wheatley, 2001). This theory proposes specific problems with serially focusing attention, either through rapid attentional capture or with attentional disengagement (Valdois, Bosse \& Tainturier, 2004). In this regard, Pammer, Lavis, Hansen and Cornelissen (2004) found evidence that problems with attentional focusing contribute to anomalies in relative position coding in dyslexia. Specifically, they found that accurate symbol string recognition was negatively affected by adjacent symbol reversals. Thus, while attentional disturbances could affect reading in their own right, visual attention deficits may manifest as letter position coding errors as well.

To study in detail the trend that we found previously for group differences of print size effects on reading performance, we compared reading rates as a function of print size for groups of children with and without dyslexia. We measured reading rate across a range of twelve print sizes from -0.2 to $1.0 \log$ MAR (corresponding to a range of 20/12 to 20/200 Snellen letter sizes, or $0.037 \mathrm{~cm}$ to $0.582 \mathrm{~cm}$ in $\mathrm{x}$-height values) for each individual, and fit the reading rate by print size curves with a two-limb fit that has been found to characterise skilled reading (Mansfield, Legge \& Bane, 1996). The two-limb fit captures how reading rates are typically constant across a range of large print sizes, then drop off rapidly below a critical print size (for example, see Figure 1).

If dyslexic readers have a magnocellular deficit that impacts letter position coding, we would expect to see a threshold effect of print size, where letter position coding is accurate and contributes to word recognition only above that threshold, and position coding breaks down for very tiny letters. Our method also allowed us to investigate the alternative possibility that dyslexic readers have a preferred print size that facilitates faster reading, rather than the normal broad range, possibly related to idiosyncrasies in their sensitivity to different spatial frequencies.

\section{Method}

\section{Participants}

Thirty-four children (22 dyslexic and 12 non-dyslexic) between 6.3 and 10.4 years of age participated in the study. The children were recruited from first to fourth grade classrooms at public schools in the vicinity of Boston, Massachusetts. Classroom teachers identified children who were either struggling readers or who were average readers in their class. Screening measures, including standardised reading and brief intelligence tests, were administered to all children. The children with dyslexia made up a sub-set of children taking part in a larger-scale intervention project (Morris, Wolf \& Lovett, 1996) and they satisfied exclusionary criteria of being primary English speakers, and being free of any neurological or psychological disorders and visual or hearing impairments. They met either a low achievement or a discrepancy eligibility criterion of developmental dyslexia. Low achievement was defined as scoring one standard deviation below the norm on either the Woodcock Reading Mastery Test-Revised (WRMT-R) (Woodcock, 1987) Basic Skills or Total Reading clusters, or on the average of the WRMT-R Word Identification, Word Attack and Passage Comprehension sub-tests and the Wide Range Achievement Test-3 (WRAT-3) (Wilkinson, 1983) Reading sub-test. A discrepancy was defined as a significant difference of at least one standard deviation between achievement on any of these three composite reading scores (WRMT-R Basic Skills, Total Reading or the average score described above) and ability (based on Full Scale IQ from either the Kaufman Brief Intelligence Test (KBIT) (Kaufman \& Kaufman, 1990), the Wechsler 
Intelligence Scale for Children (WISC-III) (Wechsler, 1991) or the Wechsler Abbreviated Scale of Intelligence (WASI) (Wechsler, 1999)). ${ }^{1}$ Six children met a low achievement criterion, six met a discrepancy criterion and ten met both criteria. The non-dyslexic children were administered the WASI and the same WRMT-R sub-tests as the children with dyslexia. Non-dyslexic children scored within the normal range on these reading measures. Table 1 provides each participant's grade, age, gender, IQ and reading scores.

Because the dyslexic children's reading ability was generally one or more years below their grade level, the non-dyslexic comparison group was chosen to match them with regard to reading level instead of grade level in school. Thus, the non-dyslexic group was younger (Mean age $=7.6$, Mean grade level $=2.0)$ than the dyslexic group $($ Mean age $=8.9$, Mean grade level $=2.8)\left(F_{(1,32)}=21.4, p<0.01\right.$ for age, and $F_{(1,32)}=6.5, p=0.02$ for grade). There was overlap in the ages and grade levels between the groups: dyslexic children were enrolled in Grades 2 to 4 and non-dyslexic children were enrolled in Grades 1 to 3. Comparison between both reading matched and grade matched controls could thereby be made for some of the children in the dyslexic group. Therefore, data for the groups are presented both by chronological grade and reading grade equivalent levels (based on word identification scores from the WRMT-R). While grade level differed between the groups, word reading grade equivalent level did not $\operatorname{differ}\left(F_{(1,32)}=0.4, p=0.53\right.$, non-dyslexic Mean $=2.6(S E=0.87)$, dyslexic Mean $=2.8$ $(S E=0.66))$. Likewise, word identification raw scores did not differ between the groups $\left(F_{(1,32)}=2.6, p=0.12\right.$, non-dyslexic Mean $=44.7(S E=4.82)$, dyslexic Mean $=52.1(S E=$ $2.24)$ ).

\section{Procedure}

Children were asked to read aloud sentences presented as black print on white paper. Each sentence was printed on its own page in a flip book. The sentence was presented by flipping the page after the child indicated that he/she was ready. Sentences were constructed so that all had 60 characters, including spaces between words and at the end of each line, formatted into three lines of left-right justified text in Times-Roman font, similar to the MNREAD sentences of Mansfield, Legge and Bane (1996) (see Appendix). Sentences were presented at a viewing distance of $40 \mathrm{~cm}$. This was maintained by verifying the viewing distance throughout the reading trials. A black card extending $40 \mathrm{~cm}$ from the flip book was placed on the table at which the children sat. The edge of the black card was aligned with the child's face, and they were told to keep their head in place 'in line with the card', just as they would keep their feet at the free-throw line when playing basketball. Any trials where the children leaned over the line were rerun with a different sentence. Thirteen levels of print size were presented in descending order ranging from 1.0 to $-0.2 \log$ MAR in $0.1 \log$ MAR steps - i.e., from 0.582 to $0.037 \mathrm{~cm} x$-heights corresponding to Snellen ratios from 20/200 to 20/12. There were two to three trials per print size.

Children read a practice sentence first, and were told that the letters would get smaller on each trial. They were instructed to read each sentence as quickly as they could, and to read as many words as they could see even if they thought they were guessing. Time to read each sentence was recorded with a stopwatch, commencing when the page was flipped and finishing when the child completed reading the last word. Reading errors were noted and used to calculate reading rates as correctly read words per minute. Sessions were also audio-taped to verify reading errors.

\footnotetext{
${ }^{1}$ All children with dyslexia were administered the KBIT at screening and either the WISC-III or the WASI after screening as part of their participation in the intervention
} 


\section{Results}

\section{Individual data}

Each participant's raw data was plotted as reading rate (correct words read per minute) as a function of print size. These data were fit with a two-limb function, where a flat portion signified maximum reading speed above a critical print size, and where reading speed dropped off rapidly below the critical print size (CPS). The individual plots yielded maximum reading speeds and critical print sizes for each individual. Examples of typical individual reading speed by print size plots in Figure 2 show that the two-limb function provided a good fit to dyslexic as well as non-dyslexic readers, supporting the hypothesis that dyslexic print size-by-reading rate curves follow the typical two-limbed form. Estimates of goodness of fit for the two-limb function did not differ between groups (RMS error, $p=0.58$ ), so the two-limb function provided an equally good fit for both groups. R-squares for all fits were significant $(p<0.05)$ with the exception of one non-dyslexic child (ND7). Inspection of this child's data indicated that her print size-by-reading speed plot did show the typical two-limb shape. One dyslexic participant's (D18) print size-by-reading speed plot did not show the typical two-limb shape; his reading speed was fairly flat across the range of print sizes. Examination of the two-limb fit parameters revealed that this child was an outlier with regard to critical print size. This participant's critical print size was more than three standard deviations above the group mean, and was estimated to be higher than the largest print size tested. This participant's data was therefore not included in the group analyses.

Maximum reading speed and critical print size were compared between dyslexic and nondyslexic groups. To determine whether a specific print size facilitated dyslexic reading exclusively, the fastest single reading speed upon the maximum reading speed plateau was obtained for each participant. The print size at which this fastest rate occurred and the magnitude of its difference from the plateau was compared between groups.

\section{Group comparisons}

Our primary interest was to investigate visual factors in dyslexic reading independent of general reading ability level. To this end the groups were selected to have comparable reading level skills, and they therefore differed in age (the dyslexic group was older). In addition, we used word reading scores (WRMT-R word identification raw scores) as a covariate in the between group analyses of print size to statistically control for reading skill. We also report separate tests covarying age and IQ, since IQ has been found to account for sensory detection threshold differences in reading disability (Hulslander et al., 2004).

MANCOVAs were run on two sets of dependent variables: (1) those from the two-limb fits (maximum reading speed, critical print size), and (2) those from the point of the single fastest reading speed (the print size supporting the fastest rate, and its difference from the reading speed plateau). Each analysis used a between factor of group (dyslexic versus non-dyslexic) and covaried word identification scores.

For the first MANCOVA, the omnibus effect for group was significant (Wilk's Lambda $\left.F_{(1,29)}=11.2, p<0.001\right)$. Subsequent univariate tests revealed significant group differences in maximum reading speed (adjusted means of $109.1 \mathrm{wpm}(S E=5.7)$ versus $81.9 \mathrm{wpm}$ ( $S E=$ 4.2) for non-dyslexic and dyslexic groups, respectively) $\left(F_{(1,30)}=14.1, p=0.001\right)$, and critical print size (adjusted means of $0.136 \operatorname{logMAR}(S E=0.04)$ versus $0.258 \log$ MAR $(S E=0.03)$ for non-dyslexic and dyslexic groups respectively) $\left(F_{(1,30)}=7.0, p=0.013\right)$. This $0.122 \log$ unit difference in critical print size corresponds to a factor of 1.32 difference in critical print sizes: that is, the dyslexic group required letters that were $32 \%$ larger than the controls to achieve their fastest reading speeds. Group means are presented by grade level (Table 2) and 
by reading grade equivalent (Table 3 ). It should be noted that critical print size differs from reading acuity, which is the smallest letter size for which one can read anything at all. The groups' reading acuities, as determined with a letter-by-letter method described in Mansfield, Legge and Bane (1996), also differed with word identification covaried $\left(F_{(1,30)}=10.4\right.$, $p<0.01)$.

Individual maximum reading speed and critical print size data are plotted as histograms by group, grade and grade equivalent in Figure 3. Interestingly, the histograms show the trend across all the subjects of a decrease in critical print size with grade level. For older children, the threshold for attaining maximum reading rates was lower (i.e. occurred at smaller print sizes). The critical print size distributions for the dyslexic group were shifted to higher thresholds (i.e. larger print) when compared to the controls of either the same chronological grade or reading grade level. In some cases, this shift to a higher critical print size for dyslexic readers was related to a shallower slope on the descending limb of the curve fit. A betweengroup ANCOVA with the word identification covariate showed a significant group difference in slopes $\left(F_{(1,30)}=4.2, p=0.04\right.$, mean slopes of $5.2(S E=0.67)$ and $3.5(S E=0.50)$ for nondyslexic and dyslexic groups, respectively). As Figure 4 shows, the group difference in slopes occurs primarily for early readers at word reading levels equivalent to Grades 1 and 2.

With age and full-scale IQ entered as covariates into the MANCOVA investigating the twolimb fit parameters, the same pattern of results emerges where the groups differ significantly in maximum reading speed and critical print size. When IQ alone is covaried in the MANCOVA, the group differences are no longer significant. This follows the findings of Hulslander et al. (2004), where full-scale IQ accounted for the relation between auditory and visual processing with word reading. Here, though, IQ was not significantly correlated with either maximum reading speed or critical print size over the whole group. Within the dyslexic group the two-limb fit parameters did not differ between groups with or without an IQachievement discrepancy or between groups of low achievers versus average achievers. Comparing the dyslexic children who met a low achievement criterion only with those who met a discrepancy criterion only and those who met both criteria showed that those meeting both criteria had the highest critical print sizes $($ Mean $=0.306$ ), followed by the discrepancy only group (Mean $=0.202$ ) and then the low-achievement only group (Mean $=0.179)$. Thus, the group with lower IQ, the low achievement group, also had the lowest critical print size of dyslexic sub-groups. So a lower IQ does not appear to account for higher critical print size.

The second MANCOVA revealed no significant group differences for either the print size supporting the fastest reading speed or the magnitude of the difference between the single fastest reading speed and the speed on the plateau. This was true when the magnitude of the reading speed difference was normalised according to one's maximum rate on their plateau (determined from the two-limb fits) or to the standard deviation of speeds about their plateau. In other words, the group effect was not significant when the magnitude difference was entered in words per minute, as a percentage of the plateau speed or in individual standard deviation units. In fact, the group means tend in the opposite direction than predicted: the non-dyslexic mean shows larger increases from the reading speed plateau $(26.1 \mathrm{wpm}(S E=2.7))$ than the dyslexic mean $(22.6 \mathrm{wpm}(S E=2.0))$. This same pattern of results was obtained when age and full-scale IQ were entered as covariates instead of word identification scores.

Lastly, we investigated the relationship between maximum reading speed and critical print size to see whether those dyslexic children with more severe reading difficulty (e.g. those with the slowest reading rates) also had larger critical print sizes. Across all participants, maximum reading speed and critical print size were significantly correlated $(r=-0.436, p=0.01)$, but only remained significant within the non-dyslexic group $(r=-0.818, p=0.001)$, and not the dyslexic group $(r=-0.227, p=0.32)$ (see Figure 5). Screening for apparent outliers revealed 
only two participants (one dyslexic and one non-dyslexic) with residuals above two standard deviations. Removing both of these individuals from the analysis did not change the pattern of the outcome: the non-dyslexic correlation was significant $(r=0.86=, p<0.001)$, and the dyslexic correlation was not $(r=-0.424, p=0.06)$, although there was a trend. The correlation for non-dyslexics was still significantly larger than that for the dyslexics $\left(z^{\prime}\right.$ difference $=2.01$, $p<0.05)$.

\section{Discussion}

Dyslexic and non-dyslexic children demonstrated similar profile shapes of reading rate across print size, profiles that follow the typical two-limb shape found previously for adults (Mansfield, Legge \& Bane, 1996). We found a similar consistency of curve profiles between dyslexic and non-dyslexic readers when we measured reading rates by luminance contrast of text and background (O'Brien, Mansfield \& Legge, 2000). Thus, print size and print contrast are visual variables for which dyslexic reading speed exhibits the same qualitative dependence - a two-limb shape that typifies skilled reading.

Although the dyslexic profiles had the normal shape, two characteristics of the two-limb fits did differ for the dyslexic readers. As expected, their maximum reading speed along the plateau was slower than that of the non-dyslexic readers even though they were older and with control for word identification skill. Also, their critical print sizes were larger than those of the controls, indicating that they needed larger print to support maximum reading rates. The group difference in critical print size was partially due to a difference in slopes of the descending portion of the two-limb fits. Dyslexic readers' shallower slopes were moderately correlated with larger critical print sizes $(r=-0.58)$.

These results confirm the hypothesis that dyslexic print size-by-reading rate curves have the typical two-limbed form but larger critical print sizes, and refute the alternative hypothesis of a monotonic increase of dyslexic reading rates with increasing print size. What could theoretically account for these results? Reading words with very small letters may prove difficult either because the letters are hard to identify or because it is hard to determine where they appear in the word. Models of reading hold that both letter identification and letter position coding play important roles in word identification (e.g. Adams, 1979; Estes \& Brunn, 1987). Thus, slow, inaccurate word identification with small letters could be due to either compromised letter identification or letter position coding.

Letter recognition and reading normally require a critical spatial frequency bandwidth. The idea that dyslexic readers need larger print to compensate for a higher or broader spatial frequency bandwidth for reading does not account for the findings, since one would expect reading performance to keep improving with increasing print size if this were the case. Likewise, the idea that dyslexic readers may have a particular print size where reading performance peaks, due to differential sensitivity to specific spatial frequencies, was also not borne out. There were no points above critical print size where reading was more efficient for the dyslexic readers.

Letter recognition alone is not sufficient for word identification and reading; rather inter-letter effects also need to be taken into account. Knowing the position of a letter relative to the other letters in a word is necessary for correct word identification; for example, distinguishing the orthographic input of 'trap' versus 'tarp' or 'part' requires correctly locating the spatial arrangement of the letters in the word. The magnocellular channel may carry a code for the relative position of each letter in the word; for instance, [t-1], [r-2], [a-3], [p-4]. This channel may contain more noise in dyslexic readers, so the numbers for ' $r$ ' and ' $a$ ' in our example may contain some uncertainty (e.g. for position 2 in the word there is a $60 \%$ chance it is the ' $r$ ' that I saw and a 40\% chance it is the ' $a$ '). Cornelissen and Hansen (1998) describe how relative 
letter position information is contained within an intermediate spatial scale of the visual stimulus (i.e. the print), while information about whole words and letter features is carried by coarse and fine scales, respectively.

For very tiny print, the fine spatial scale must become too small to resolve critical features, so letters cannot be identified and the acuity limit is reached. Just above this point, letters can be resolved but may not be ordered correctly because of noise (spatial uncertainty) in the codes for spatial position. Theoretically, greater relative position noise in dyslexia may contribute to slow reading in general, and could cause dyslexic reading to be more susceptible to deterioration with small print: meaning dyslexic readers should have slower maximum reading speeds and higher critical print sizes. The present results are consistent with a dyslexic magnocellular-letter position coding deficit.

Other related accounts of inter-letter effects on word reading include crowding, visual attention and visual span. Crowding, or lateral masking, refers to the hindering of letter recognition when a letter is flanked by other letters. The difference in curve shape for dyslexic readers could be because of greater susceptibility to crowding effects, especially if their recognition of isolated letters is already inaccurate or slow. Indeed, previous studies have found greater crowding effects for dyslexic readers (Atkinson, 1999; Geiger \& Lettvin, 1987). Klein and D'Entremont (1999) found greater interference between far flankers than near ones for dyslexics, which they attributed to differences in visual attentional filtering. While it is unclear how visual attention differences per se could account for the present print size effect in dyslexia, two theories are relevant. First, visual attention could be the cognitive module that mediates between magnocellular function at the physiological level and position coding for letters in words (e.g. see Pammer et al., 2004). Second, visual attention may impact the visible window of text while reading. Ans, Carbonnel and Valdois (1998) developed a connectionist model of reading that uses a visual attention window, wherein maximal parallel processing occurs, and which is modified in size based on reading mode. The attentional window in this model can be narrowed to focus on smaller portions of orthographic input if needed. This notion of a reader's attentional control over the number of letters processed at a glance may be related to the concept of visual span, the number of letters one can recognise at a glance (O'Regan, Levy-Schoen \& Jacobs, 1983). Legge et al. $(1997,2001,2002)$ systematically studied visual span size with regard to print size, and found that visual span decreases with very small and very large letters, and that reading speed covaries with the size of the visual span. Normally, smaller visual spans (in characters) are found for print sizes smaller than the critical print size. The present finding of a difference in curve shape for dyslexic readers could be because of a difference in their visual span. That is, we would predict that dyslexic visual spans may continue to increase with increasing print size to a somewhat larger print size (corresponding to the increased critical print size), and the size of the visual span may be smaller than normal even above the critical print size. These potential differences in visual span may be related to inter-letter effects such as crowding or attentional resolution.

While each of these theoretical accounts - position coding, crowding, visual attention or visual span - could contribute to the present print size effect for dyslexic readers, the theories are not mutually exclusive; rather they are likely to be related. For example, imprecise letter position coding could result from attentional disturbances or increased crowding effects in dyslexia. Huckauf and Heller (2002) demonstrated that crowding effects could be explained by position uncertainty rather than interactions of adjacent letter forms. Teasing apart letter position coding and crowding effects on dyslexic reading would require further study by independently manipulating print size and letter spacing. Furthermore, both position uncertainty and crowding effects may contribute to the extent of one's visual span for reading. 
It is also possible that a magnocellular deficit could be manifest as slower reading with small text in the present study because of oculomotor factors. The magnocellular visual pathway has neural connections with areas involved in eye-movement programming (e.g. the superior colliculus). Because reading, as in the present study, requires a succession of saccadic eye movements, a magnocellular deficit could have an impact at this level instead of or in addition to a letter-position coding deficit. Producing eye movements within text with small print may be especially difficult, as Kowler and Anton (1987) found that very small saccades may take longer to produce. The present study cannot speak to this possibility. An investigation comparing print size effects of text presentations with and without required eye movements (e.g. normal page-formatted text versus rapid serial visual presentation (RSVP)) would be required to differentiate these effects.

Because the dyslexic group was older in the present sample, one could speculate that the characteristic differences of the two-limb curves result from a general developmental lag, where dyslexic readers behave like younger non-dyslexic readers with regard to having slower maximum reading rates and higher critical print sizes. That the groups still differed when reading level was controlled runs counter to this claim. We chose to 'equate' the reading groups on isolated word identification, although other factors may be developmentally relevant as well. Furthermore, a developmental lag model would be strongly supported if the dyslexic and non-dyslexic data fell on the same critical-print size-by-maximum-reading-rate regression line, but this was not the case either. The dyslexic group showed a lack of a correlation between these variables, whereas the nondyslexic group showed a fairly strong correlation. This implies some de-coupling of the maturational influences that normally tie the two variables together. Here, the slowest dyslexic readers did not necessarily require larger print size thresholds to attain their maximum reading speed, whereas slower non-dyslexic readers did.

One might also expect that if general intelligence accounts for sensory processing differences in dyslexia, then those with lower IQ would show the greatest impact on sensory processing (i.e. they would have higher critical print sizes). However, this did not appear to be the case with the group we tested. It was the children with higher IQ and an IQ-achievement discrepancy who actually had the highest critical print sizes.

Lastly, it is of interest in understanding the development of normal reading behaviour that the non-dyslexic group showed effects of age on critical print size as well as maximum reading speed. Increasing reading rates with age conforms to previous findings of a linear increase between 10 and 20 wpm per grade (Carver, 1990; Tressoldi, Stella \& Faggella, 2001). We are not aware of any previous research findings showing the developmental change in critical print size. Our data showed that critical print size decreases with age, suggesting younger children need larger print to optimise reading performance. It is noteworthy that reading materials for early, very young readers generally have larger print than texts for older children. We also found a negative correlation between reading speed and critical print size, showing that in general slower non-dyslexic readers required larger print size to support their maximum reading speed. The finding that dyslexic readers require larger print size to attain their maximum reading speed has implications for the type of print that educators select for these children (e.g. see Hughes \& Wilkins (2002) regarding general recommendations for print size and spacing in children's books for group reading).

\section{Acknowledgements}

This work was supported in part by NIH Grants HD30970 and EY 02934. We wish to thank the families, teachers and schools of our participants for their co-operation and support. We also thank the anonymous reviewers for their helpful comments. 


\section{References}

Adams MJ. Models of word recognition. Cognitive Psychology 1979;11(2):133-176.

Ans B, Carbonnel S, Valdois S. A connectionist multi-trace memory model of polysyllabic word reading. Psychological Review 1998;105:678-723. [PubMed: 9830376]

Atkinson, J. Vision in dyslexics: Letter recognition, acuity, visual crowding, contrast sensitivity, accommodation, convergence and sight reading music. In: Wright, SF.; Groner, R., editors. Facets of dyslexia and its remediation. Elsevier Science; Amsterdam: 1993.

Carver, RP. Reading rate: A review of research and theory. Academic Press; San Diego: 1990.

Chin CE, Ledesma HML, Cirino PT, Sevcik RA, Morris RD, Frijters JC, Lovett MW. Relation between Kaufman Brief Intelligence Test and WISC-III scores of children with RD. Journal of Learning Disabilities 2001;34(1):2-8. [PubMed: 15497268]

Cornelissen P, Bradley L, Fowler S, Stein J. What children see affects how they read. Developmental Medicine and Child Neurology 1991;33:755-762. [PubMed: 1936628]

Cornelissen PL, Richardson AL, Mason A, Fowler MS, Stein JF. Contrast sensitivity and coherent motion detection measured at photopic luminance levels in dyslexics and controls. Vision Research 1994;35:1483-1494. [PubMed: 7645277]

Cornelissen PL, Hansen P, Gilchrist I, Cormack F, Essex J, Frankish C. Coherent motion detection and letter position encoding. Vision Research 1998a;38:2181-2191. [PubMed: 9797977]

Cornelissen PL, Hansen P, Hutton J, Evangelinou V, Stein J. Magnocellular visual function and children's single word reading. Vision Research 1998b;38:471-482. [PubMed: 9536370]

Cornelissen PL, Hansen PC. Motion detection, letter position encoding, and single word reading. Annals of Dyslexia 1998;48:155-188.

Demb JB, Boynton GM, Heeger DJ. Brain activation in visual cortex predicts individual differences in reading performance. Proceedings of the New York Academy of Sciences 1997;94:13363-13366.

Demb JB, Boynton GM, Best M, Heeger D. Psychophysical evidence for a magnocellular deficit in dyslexics. Vision Research 1998;38:1555-1559. [PubMed: 9747491]

Eden GF, van Meter JW, Rumsey JW, Maisog J, Zeffiro TA. Functional MRI reveals differences in visual motion processing in individuals with dyslexia. Nature 1996;382:66-69. [PubMed: 8657305]

Estes WK, Brunn JL. Discriminability and bias in the word-superiority effect. Perception and Psychophysics 1987;42(5):411-422. [PubMed: 3696936]

Everatt J, Bradshaw MF, Hibbard PB. Visual processing and dyslexia. Perception 1999;28(2):243-254. [PubMed: 10615463]

Galaburda, AM.; Livingstone, MS. Evidence for a magnocellular defect in developmental dyslexia. In: Tallal, P.; Galaburda, AM.; Llinas, RR.; von Euler, C., editors. Temporal information processing in the nervous system. 682. Annals of the New York Academy of Sciences; 1993. p. 70-82.

Geiger G, Lettvin JY. Peripheral vision in persons with dyslexia. New England Journal of Medicine 1987;316:1238-1243. [PubMed: 3574384]

Hays JR, Reas DL, Shaw JB. Concurrent validity of the Wechsler Abbreviated Scale of Intelligence and the Kaufman Brief Intelligence Test among psychiatric inpatients. Psychological Reports 2002;90 (2):355-359. [PubMed: 12061569]

Huckauf A, Heller D. What various kinds of errors tell us about lateral masking effects. Visual Cognition 2002;9(7):889-910.

Hughes LE, Wilkins AJ. Reading at a distance: Implications for the design of text in children's big books. British Journal of Educational Psychology 2002;72(2):213-226. [PubMed: 12028609]

Hulslander J, Talcott J, Witton C, DeFries J, Pennington B, Wadsworth S, Willcutt E, Olson R. Sensory processing, reading, IQ, and attention. Journal of Experimental Child Psychology 2004;88:274-295. [PubMed: 15203301]

Iles J, Walsh V, Richardson A. Visual search performance in dyslexia. Dyslexia 2000;6:163-177. [PubMed: 10989565]

Kaufman, AS.; Kaufman, NL. Kaufman brief intelligence test. American Guidance Services; Circle Pines, MN: 1990. 
Klein RM, Berry G, Briand K, D'Entremont B, Farmer M. Letter identification declines with increasing retinal eccentricity at the same rate for normal and dyslexic readers. Perception and Psychophysics 1990;47:601-606. [PubMed: 2367180]

Klein, RM.; D'Entremont, B. Filtering performance by good and poor readers. In: Everatt, J., editor. Reading and dyslexia: Visual and attentional processes. Routledge, Taylor \& Francis Group; New York, NY: 1999.

Kowler E, Anton S. Reading twisted text: Implications for the role of saccades. Vision Research 1987;27:45-60. [PubMed: 3617546]

Legge GE, Ahn SJ, Klitz TS, Luebker A. Psychophysics of reading - XVI. The visual span in normal and low vision. Vision Research 1997;37(14):1999-2010. [PubMed: 9274784]

Legge GE, Lee H-W, Owens D, Cheung S-H, Chung STL. Visual span: A sensory bottleneck on reading speed. Journal of Vision 2002;2(7):279.

Legge GE, Mansfield JS, Chung STL. Psychophysics of reading - XX. Linking letter recognition to reading speed in central and peripheral vision. Vision Research 2001;41:725-743. [PubMed: 11248262]

Legge GE, Pelli DG, Rubin GS, Schleske MM. Psychophysics of reading - I. Normal vision. Vision Research 1985;25(2):239-252. [PubMed: 4013091]

Liberman IY, Shankweiler D, Fischer FW, Carter B. Explicit syllable and phoneme segmentation in the young child. Journal of Exceptional Child Psychology 1974;18:201-212.

Livingstone MS, Rosen GD, Drislane FW, Galaburda AM. Physiological and anatomical evidence for a magnocellular deficit in developmental dyslexia. Proceedings of the National Academy of Sciences (USA) 1991;88:7943-7947.

Lovegrove WJ, Martin F, Blackwood M, Badcock D. Specific reading difficulty: Differences in contrast sensitivity as a function of spatial frequency. Science 1980;210:439-440. [PubMed: 7433985]

Lovett MW, Steinbach KA, Frijters JC. Remediating the core deficits of developmental reading disability: A double-deficit perspective. Journal of Learning Disabilities 2000;33(4):334-358. [PubMed: 15493096]

Lyon GR, Moats LC. Critical conceptual and methodological considerations in reading intervention research. Journal of Learning Disabilities 1997;30:578-588. [PubMed: 9364895]

Mansfield JS, Legge GE, Bane MC. Psychophysics of reading - XV: Font effects in normal and low vision. Investigative Ophthalmology \& Visual Science 1996;37(8):1492-1501. [PubMed: 8675391]

Martin F, Lovegrove WJ. Flicker contrast sensitivity in normal and specifically disabled readers. Perception 1987;16:215-221. [PubMed: 3684483]

Mishkin M, Ungerlieder LG, Macko KA. Object vision and spatial vision: Two cortical pathways. Trends in Neuroscience 1983;1010:3323-3334.

Morgan WP. Word blindness. British Medical Journal 1896;2:1378.

MorrisRWolfMLovettMThe treatment of developmental reading disabilities1996HD 30970

O'Brien BA, Mansfield JS, Legge GE. The effect of contrast on reading speed in dyslexia. Vision Research 2000;40:1921-1935. [PubMed: 10837835]

O'Regan JK, Levy-Schoen A, Jacobs AM. The effect of visibility on eye-movement parameters in reading. Perception and Psychophysics 1983;34:457-464. [PubMed: 6657450]

Orton ST. Specific reading disability - Strephosymbolia. Journal of the American Medical Association 1928;90:1095-1099.

Pammer K, Wheatley C. Isolating the M(y)-cell response in dyslexia using the spatial frequency doubling illusion. Vision Research 2001;41:2139-2147. [PubMed: 11403797]

Pammer K, Lavis R, Hansen P, Cornelissen P. Symbol-string sensitivity and children's reading. Brain and Language 2004;89:601-610. [PubMed: 15120551]

Prewett PN. A comparison of two screening tests (the Matrix Analogies Test-Short Form and the Kaufman Brief Intelligence Test) with the WISC-III. Psychological Assessment 1995;7(1):69-72.

Skottun BC. The magnocellular deficit theory of dyslexia: The evidence from contrast sensitivity. Vision Research 2000;40:111-127. [PubMed: 10768046]

Skottun BC. Is dyslexia caused by a visual deficit? Vision Research 2001;41:3070.

Snowling, MJ. Dyslexia. 2nd. Blackwell Publishers; Malden, MA: 2000. 
Solomon JA, Pelli DG. The visual filter mediating letter identification. Nature 1994;369:395-397. [PubMed: 8196766]

Stanovich KE, Siegel LS. Phenotypic performance profile of children with reading disabilities: A regression-based test of the phonological-core variable-difference model. Journal of Educational Psychology 1994;86(1):24-53.

Talcott JB, Hansen PC, Elikem LA, Stein JF. Visual motion sensitivity in dyslexia: Evidence for temporal and motion energy integration deficits. Neuropsychologia 2000;38:935-943. [PubMed: 10775704]

Talcott JB, Hansen PC, Willis-Owen C, McKinnell IW, Richardson AJ, Stein JF. Visual magnocellular impairment in adult developmental dyslexics. Neuro-ophthalmology 1998;20:187-201.

Thompson A, Browne J, Schmidt F, Boer M. Validity of the Kaufman Brief Intelligence Test and a foursubtest WISC-III short form with adolescent offenders. Assessment 1997;4(4):385-394.

Torgesen JK. Individual differences in response to early interventions in reading: The lingering problem of treatment resisters. Learning Disabilities Research \& Practice 2000;15(1):55-64.

Tressoldi PE, Stella G, Faggella M. The development of reading speed in Italians with dyslexia: A longitudinal study. Journal of Learning Disabilities 2001;34(5):414-417. [PubMed: 15503590]

Valdois S, Bosse M, Tainturier M. The cognitive deficits responsible for developmental dyslexia: Review of evidence for a selective visual attentional disorder. Dyslexia 2004;10:339-363. [PubMed: 15573964]

Walther-Muller PU. Is there a deficit of early vision in dyslexia? Perception 1995;24:919-936. [PubMed: 8848361]

Wechsler, D. Wechsler Intelligence Scale for Children. 3rd. The Psychological Corporation; Boston, MA: 1991.

Wechsler, D. Wechsler Abbreviated Scale of Intelligence. The Psychological Corporation; Boston, MA: 1999.

Wilkinson, GS. Wide Range Achievement Test - 3. Wide Range Inc; Wilmington, DE: 1993.

Wolf M, Bowers P. The 'double-deficit hypothesis' for the developmental dyslexias. Journal of Educational Psychology 1999;91(3):1-24.

Woodcock, R. Woodcock Reading Mastery Test. American Guidance Service; Circle Pines, MN: 1987. 


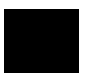

Figure 1.

Diagram of reading speed-by-print size curve, showing a two-limb fit with parameters of maximum reading speed for large print sizes ( $\max r s$ ), and critical print size ( $c p s$ ), below which reading speed drops off dramatically. Note: Also depicted is the preferred print size supporting the single fastest reading speed (pref ps) on the reading speed plateau. 

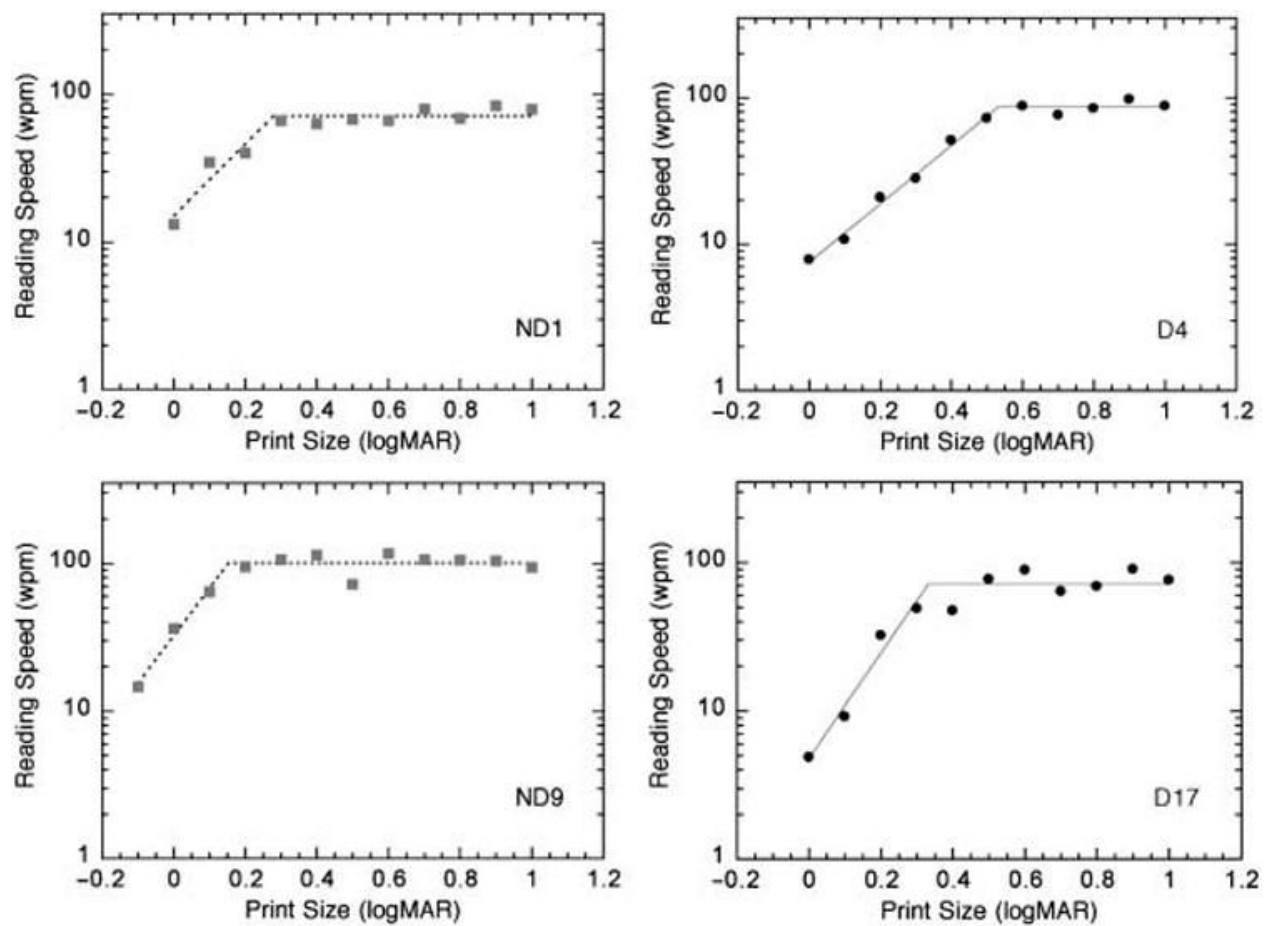

Figure 2.

Examples of individual reading speed-by-print size curves shown with two-limb fits for two non-dyslexic and two dyslexic readers. 
(A) Non Dyslexic

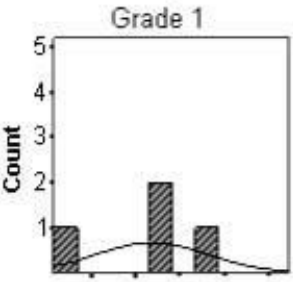

Grade 2

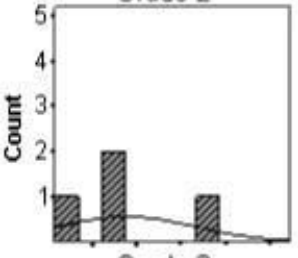

Grade 3

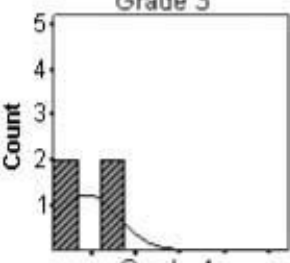

Grade 4

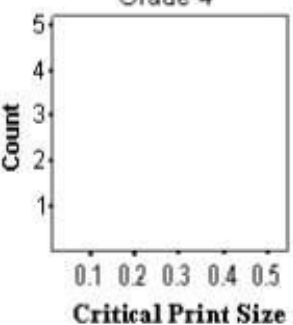

Dyslexic

Grade 1

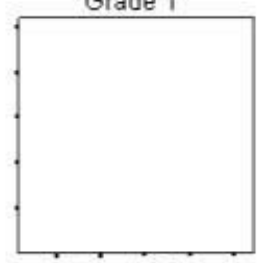

Grade 2

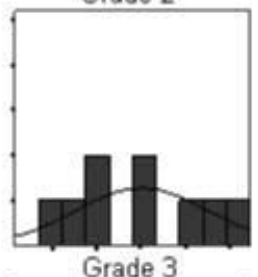

Grade 3

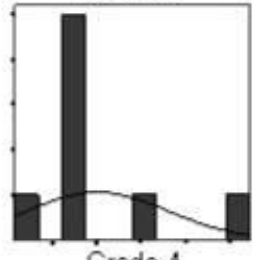

Grade 4

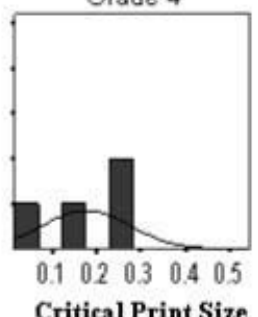

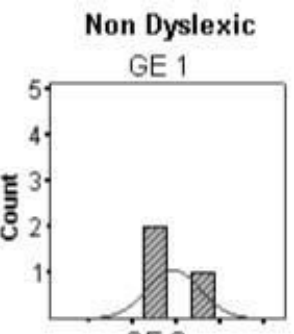

GE 2

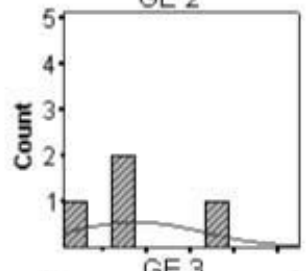

GE 3

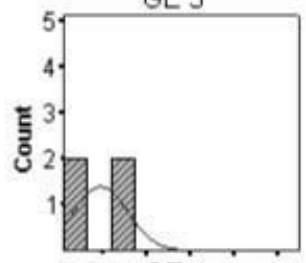

GE 4

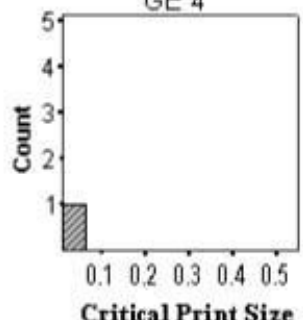

Dyslexic

GE 1

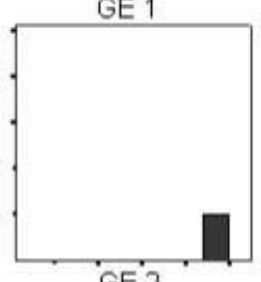

GE 2

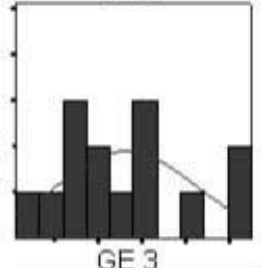

GE 3

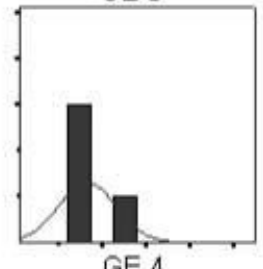

GE 4

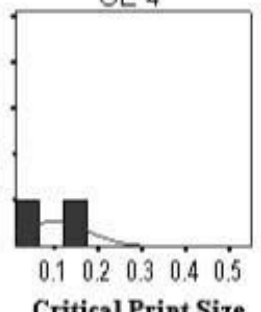

Figure 3a.

Histograms of individual data from the two-limb fits. Notes: Plots of (A) critical print size $(\log$ MAR) and (B) maximum reading speed (wpm) are shown separately for group by grade level (left columns) and for group by reading grade equivalent (GE) (based on word identification scores) (right columns). Grades corresponded to the following ages: Grade 1 (age 6), Grade 2 (ages 7 and 8), Grade 3 (ages 8 and 9), Grade 4 (age 10). 
(B) Non Dyslexic

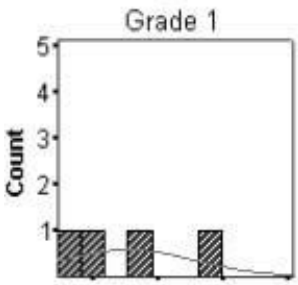

Grade 2

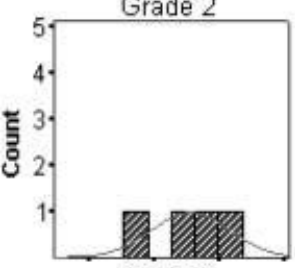

Grade 3

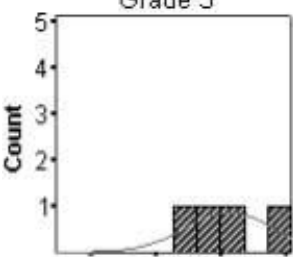

Grade 4

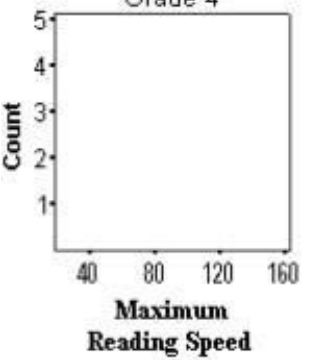

Dyslexic

Grade 1

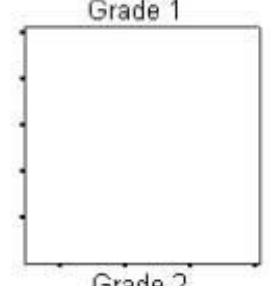

Grade 2

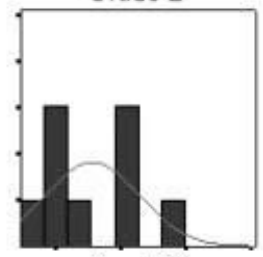

Grade 3

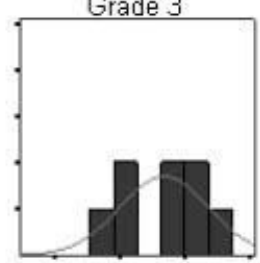

Grade 4

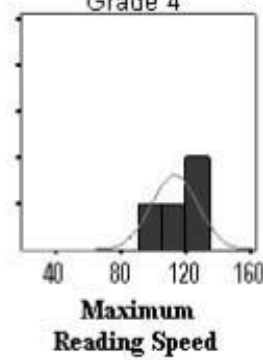

Non Dyslexic

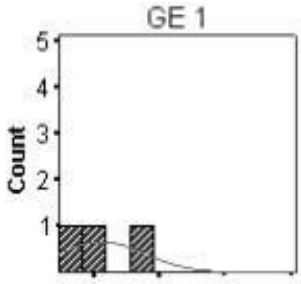

GE 2

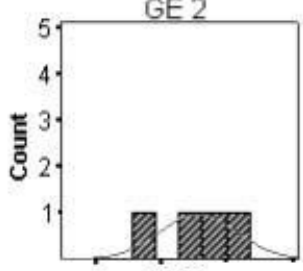

GE 3

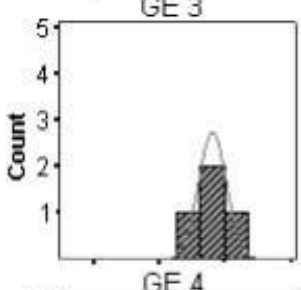

GE 4

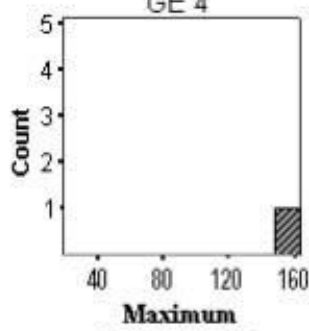

Reading Speed
Dyslexic

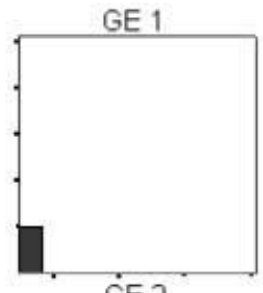

GE 2

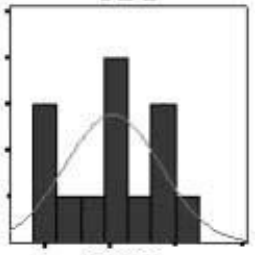

GE 3

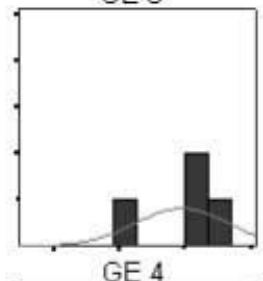

GE 4

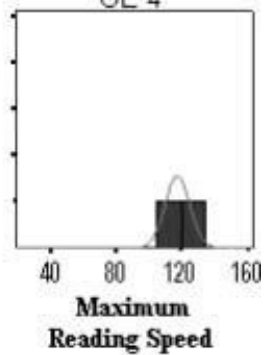

Figure 3b.

Histograms of individual data from the two-limb fits. 


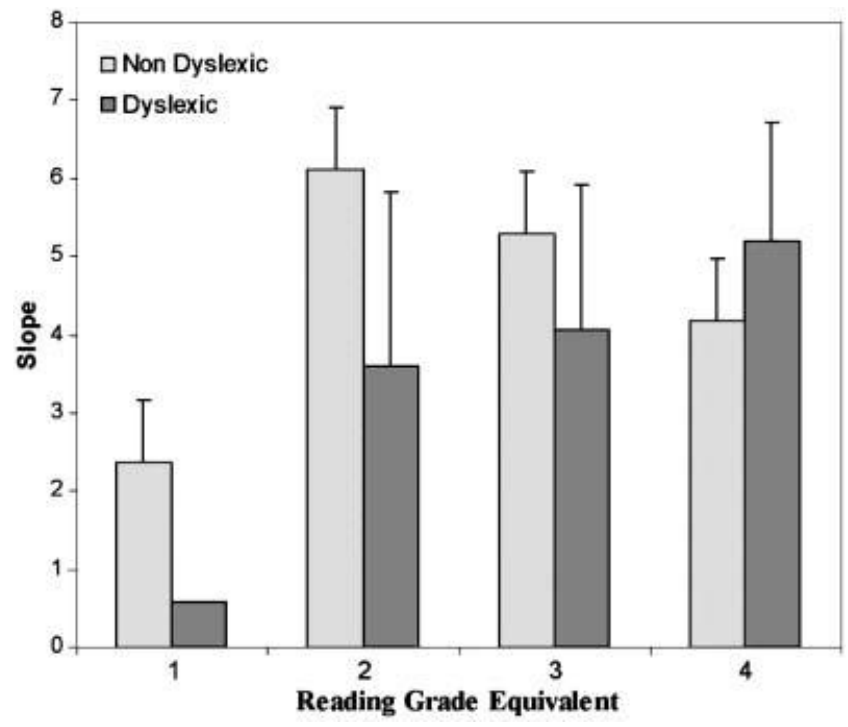

Figure 4.

Group means of slopes from the descending limb of two-limb functions, shown by reading grad equivalent (based on word identification scores). 


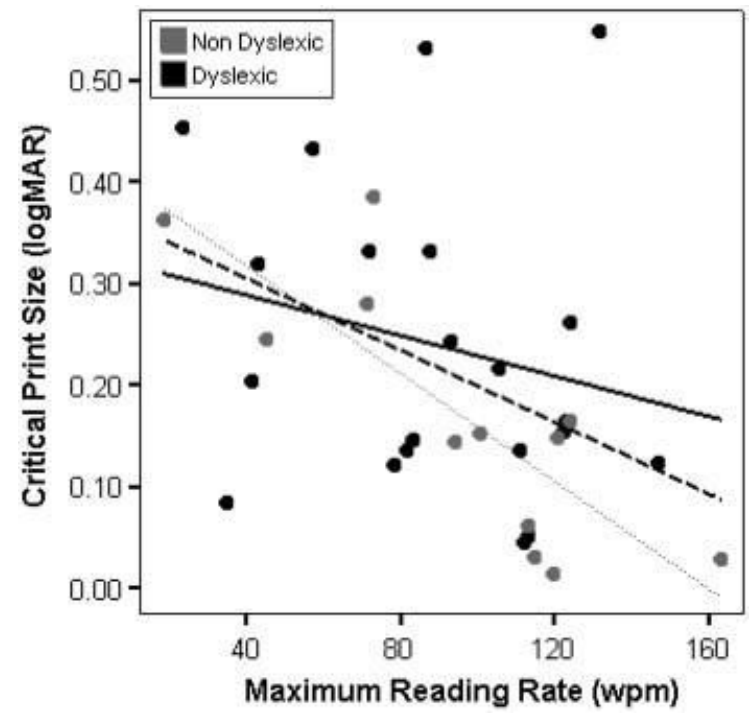

Figure 5.

Regressions of critical print size on maximum reading speed for all subjects (dashed line), and for dyslexic (solid line) and non-dyslexic (dotted line) groups. 
Table 1

Age, grade, gender, IQ and reading measures for each participant (ND = non-dyslexic, D = dyslexic).

\begin{tabular}{|c|c|c|c|c|c|c|c|c|}
\hline Subj. & Grade & Age (yrs) & Gender & FSIQ & VIQ & NVIQ & $\begin{array}{c}\text { WRMT- } \\
\text { R Basic Skill }\end{array}$ & Criterion (dyslexia) \\
\hline ND1 & 1 & 6.9 & M & $107_{\mathrm{a}}$ & 108 & 104 & 95 & none \\
\hline ND2 & 1 & 6.6 & M & $107_{\mathrm{a}}$ & 95 & 118 & 107 & none \\
\hline ND3 & 1 & 6.8 & $\mathrm{~F}$ & $88_{a}$ & 98 & 83 & 98 & none \\
\hline ND4 & 2 & 7.7 & F & $91_{\mathrm{a}}$ & 100 & 86 & 102 & none \\
\hline ND5 & 2 & 7.9 & F & $102_{\mathrm{a}}^{\mathrm{a}}$ & 101 & 102 & 94 & none \\
\hline ND6 & 2 & 7.8 & $\mathrm{~F}$ & $82_{a}$ & 80 & 86 & 100 & none \\
\hline ND7 & 2 & 7.6 & $\mathrm{~F}$ & $966_{a}$ & 93 & 99 & 105 & none \\
\hline ND8 & 3 & 8.3 & M & $98_{a}$ & 109 & 86 & 105 & none \\
\hline ND9 & 3 & 8.2 & $\mathrm{~F}$ & $94 a$ & 99 & 90 & 99 & none \\
\hline ND10 & 3 & 8.7 & $\mathrm{~F}$ & $91_{\mathrm{a}}$ & 94 & 90 & 96 & none \\
\hline ND11 & 3 & 8.5 & M & $933_{a}$ & 108 & 81 & 106 & none \\
\hline ND12 & 1 & 6.3 & $\mathrm{~F}$ & $97_{\mathrm{a}}$ & 95 & 99 & 111 & none \\
\hline D1 & 3 & 9.5 & $\mathrm{~F}$ & $84_{b}$ & 79 & 93 & 84 & LA \\
\hline D2 & 3 & 9.6 & F & $102_{\mathrm{b}}$ & 101 & 103 & 81 & BOTH \\
\hline D3 & 3 & 9.1 & F & $106_{b}$ & 110 & 102 & 85 & DISC \\
\hline D4 & 2 & 8.8 & $\mathrm{~F}$ & $95_{\mathrm{b}}$ & 92 & 99 & 82 & BOTH \\
\hline D5 & 3 & 9.3 & M & $103_{\mathrm{b}}$ & 107 & 98 & 87 & DISC \\
\hline D6 & 4 & 10.0 & $\mathrm{~F}$ & $91_{\mathrm{b}}$ & 93 & 91 & 85 & LA \\
\hline D7 & 3 & 8.8 & M & $117_{\mathrm{b}}$ & 110 & 123 & 89 & DISC \\
\hline D8 & 4 & 10.0 & $\mathrm{~F}$ & $97_{\mathrm{b}}$ & 99 & 95 & 86 & BOTH \\
\hline D9 & 4 & 10.0 & $\mathrm{~F}$ & $120_{b}$ & 112 & 125 & 85 & DISC \\
\hline D10 & 3 & 9.3 & M & $78_{\mathrm{b}}$ & 84 & 75 & 83 & LA \\
\hline D11 & 4 & 10.4 & M & $108_{c}$ & 109 & 106 & 76 & BOTH \\
\hline D12 & 2 & 8.2 & M & $83_{c}$ & 92 & 77 & 76 & ВОTH \\
\hline D13 & 2 & 8.8 & M & $97 \mathrm{a}$ & 96 & 98 & 75 & ВОTH \\
\hline D14 & 2 & 8.1 & M & $944_{a}$ & 82 & 108 & 78 & BOTH \\
\hline D15 & 2 & 7.9 & M & $92 \mathrm{a}_{\mathrm{a}}$ & 89 & 96 & 86 & LA \\
\hline D16 & 2 & 8.5 & $\mathrm{~F}$ & $81_{a}$ & 80 & 86 & 73 & ВОTH \\
\hline D17 & 3 & 9.2 & M & $108_{\mathrm{a}}$ & 98 & 117 & 79 & ВОTH \\
\hline D18 & 2 & 7.5 & M & $129 \mathrm{a}$ & 133 & 119 & 95 & BOTH \\
\hline D19 & 3 & 9.2 & $\mathrm{~F}$ & $88_{a}$ & 89 & 91 & 85 & LA \\
\hline D20 & 2 & 8.1 & $\mathrm{~F}$ & $104_{\mathrm{a}}$ & 105 & 103 & 93 & DISC \\
\hline D21 & 2 & 8.1 & M & 89 a & 98 & 84 & 84 & LA \\
\hline D22 & 2 & 8.0 & M & $98_{\mathrm{a}}$ & 102 & 93 & 88 & DISC \\
\hline
\end{tabular}

Notes: IQ measures include full-scale (FSIQ), verbal (VIQ) and non-verbal (NVIQ) quotients based on the WASI $\mathrm{a}_{\mathrm{a}}$, WISC-III $\mathrm{b}$, or KBIT $\mathrm{c}$. Basic Skill reading scores from the WRMT-R are compound standard scores from the Word Identification and Word Attack sub-tests. For participants with dyslexia, definitional criteria are also given ( $\mathrm{LA}=$ low achievement criterion met, DISC = discrepancy criterion met, BOTH = both low achievement and discrepancy criteria were met). 
Table 2

Means (standard deviations) of two-limb fit parameters by group and grade level. Maximum Reading Speed is reported in words per minute, and critical print size and reading acuity in logMAR units.

\begin{tabular}{|c|c|c|c|c|c|c|}
\hline \multirow[b]{2}{*}{ Grade } & \multicolumn{2}{|c|}{ Maximum reading speed } & \multicolumn{2}{|c|}{ Critical print size } & \multicolumn{2}{|c|}{ Reading acuity } \\
\hline & Dyslexic & Non-dyslexic & Dyslexic & Non-dyslexic & Dyslexic & Non-dyslexic \\
\hline $\begin{array}{l}1 \\
2 \\
3 \\
4\end{array}$ & $\begin{array}{r}62.45(28.8) \\
107.17(27.3) \\
112.87(14.5)\end{array}$ & $\begin{array}{r}61.97(40.5) \\
102.56(23.9) \\
124.94(26.9)\end{array}$ & $\begin{array}{l}0.302(0.15) \\
0.201(0.16) \\
0.176(0.10)\end{array}$ & $\begin{array}{l}0.237(0.13) \\
0.177(0.15) \\
0.090(0.07)\end{array}$ & $\begin{array}{l}0.237(0.18) \\
0.015(0.9) \\
0.006(0.09)\end{array}$ & $\begin{array}{r}0.206(0.17) \\
0.036(0.09) \\
-0.035(0.06)\end{array}$ \\
\hline
\end{tabular}


Table 3

Means (standard deviations) of two-limb fit parameters by group and reading grade equivalent (based on word identification scores).

\begin{tabular}{|c|c|c|c|c|c|c|}
\hline \multirow[b]{2}{*}{ READING GRADE EQUIV. } & \multicolumn{2}{|c|}{ Maximum reading speed } & \multicolumn{2}{|c|}{ Critical print size } & \multicolumn{2}{|c|}{ Reading acuity } \\
\hline & Dyslexic & $\begin{array}{c}\text { Non- } \\
\text { dyslexic }\end{array}$ & Dyslexic & $\begin{array}{c}\text { Non- } \\
\text { dyslexic }\end{array}$ & Dyslexic & $\begin{array}{c}\text { Non- } \\
\text { dyslexic }\end{array}$ \\
\hline 1 & 23.34 & $44.88(26.6)$ & 0.452 & $0.295(0.06)$ & 0.685 & \\
\hline 2 & $81.46(29.3)$ & $102.56(23.9)$ & $0.265(0.16)$ & $0.177(0.15)$ & $0.135(0.18)$ & \\
\hline 3 & $118.16(28.6)$ & $112.43(8.5)$ & $0.168(0.07)$ & $0.098(0.06)$ & $-0.023(0.04)$ & $0004(003)$ \\
\hline 4 & $117.25(7.5)$ & 163.31 & $0.100(0.08)$ & 0.028 & $-0.053(0.04)$ & $\begin{array}{l}0.004(0.03) \\
-0.120\end{array}$ \\
\hline
\end{tabular}




\section{Appendix}

\begin{tabular}{|c|c|c|c|}
\hline log்MAR & List 1 & List 2 & List 3 \\
\hline 1.0 & $\begin{array}{l}\text { The three elephants in the circus walked } \\
\text { around very slowly }\end{array}$ & $\begin{array}{l}\text { The two friends did not know what time } \\
\text { the play would start }\end{array}$ & \\
\hline 0.9 & $\begin{array}{l}\text { An old man took a picture of my sister } \\
\text { and her little puppy }\end{array}$ & $\begin{array}{l}\text { She wanted to show us the new toys she } \\
\text { got for her birthday }\end{array}$ & \\
\hline 0.8 & $\begin{array}{l}\text { Ten different kinds of flowers grow by } \\
\text { the side of the road }\end{array}$ & $\begin{array}{l}\text { The father gave his children some fruit } \\
\text { for lunch every day }\end{array}$ & $\begin{array}{l}\text { We could not guess what was inside } \\
\text { the big box on the table }\end{array}$ \\
\hline 0.7 & $\begin{array}{l}\text { Please do not make noise while they are } \\
\text { reading their books }\end{array}$ & $\begin{array}{l}\text { The snow fell softly this morning before } \\
\text { our family woke up }\end{array}$ & $\begin{array}{l}\text { The mother told her son that she } \\
\text { wanted him to go to school }\end{array}$ \\
\hline 0.6 & $\begin{array}{l}\text { Many people came to help us clean the } \\
\text { place after the party }\end{array}$ & $\begin{array}{l}\text { The teacher wanted the children to learn } \\
\text { how to draw a boat }\end{array}$ & $\begin{array}{l}\text { Put your first name on this paper if } \\
\text { you will help tomorrow }\end{array}$ \\
\hline 0.5 & $\begin{array}{l}\text { We like to listen to music when we are } \\
\text { eating our breakfast }\end{array}$ & $\begin{array}{l}\text { She gave a glass of water to her mother } \\
\text { before going to bed }\end{array}$ & $\begin{array}{l}\text { We sometimes take long walks } \\
\text { together if it is warm outside }\end{array}$ \\
\hline 0.4 & $\begin{array}{l}\text { My brother was not feeling very well so } \\
\text { he did not go today }\end{array}$ & $\begin{array}{l}\text { Everyone wanted to go outside when the } \\
\text { rain finally stopped }\end{array}$ & $\begin{array}{l}\text { He could see a bird outside if he } \\
\text { looked through his window }\end{array}$ \\
\hline 0.3 & $\begin{array}{l}\text { They were not able to finish playing the } \\
\text { game before dinner }\end{array}$ & $\begin{array}{l}\text { Three of my friends had never been to a } \\
\text { circus before today }\end{array}$ & $\begin{array}{l}\text { Three of my closest friends are } \\
\text { going to visit him tomorrow }\end{array}$ \\
\hline 0.2 & $\begin{array}{l}\text { My grandfather has a large garden with } \\
\text { fruit and vegetables }\end{array}$ & $\begin{array}{l}\text { My mother loves to hear the young girls } \\
\text { sing in the morning }\end{array}$ & $\begin{array}{l}\text { My father takes me to school every } \\
\text { day in his big green car }\end{array}$ \\
\hline 0.1 & $\begin{array}{l}\text { The young boy held his hand high to ask } \\
\text { questions in school }\end{array}$ & $\begin{array}{l}\text { I do not understand why we must leave } \\
\text { so early for the play }\end{array}$ & $\begin{array}{l}\text { My father asked me to help the two } \\
\text { men carry the box inside }\end{array}$ \\
\hline 0.0 & $\begin{array}{l}\text { It is more than four hundred miles from } \\
\text { my home to the city }\end{array}$ & $\begin{array}{l}\text { They would love to see you during your } \\
\text { visit here this week }\end{array}$ & $\begin{array}{l}\text { He told a long story about ducks } \\
\text { before his son went to bed }\end{array}$ \\
\hline-0.1 & $\begin{array}{l}\text { The teacher showed the children how to } \\
\text { draw pretty pictures }\end{array}$ & $\begin{array}{l}\text { The old man caught a fish here when he } \\
\text { went out in his boat }\end{array}$ & $\begin{array}{l}\text { My brother wanted a glass of milk } \\
\text { with his cake after lunch }\end{array}$ \\
\hline-0.2 & $\begin{array}{l}\text { There are two dogs and three cats in the } \\
\text { park near my house }\end{array}$ & $\begin{array}{l}\text { Our mother tells us that we should wear } \\
\text { heavy coats outside }\end{array}$ & $\begin{array}{l}\text { Our father wants us to wash the } \\
\text { clothes before he gets back }\end{array}$ \\
\hline
\end{tabular}

